\title{
ANÁLISE AMBIENTAL DA MICROBACIA HIDROGRÁFICA DO CÓRREGO ÁGUA DA COLÔNIA DO MUNICÍPIO DE PRESIDENTE VENCESLAU- SP
}

\section{ENVIRONMENTAL ANALYSIS OF THE WATERSHED OF THE CÓRREGO ÁGUA DA COLÔNIA IN THE MUNICIPALITY OF PRESIDENTE VENCESLAU- SP}

\author{
Beatriz Regina de ÂNGELO ${ }^{1}$, Rafaela Pelegrini VITAL ${ }^{2}$, Thaís dos Santos \\ AQUINO $^{3}$, Elson Mendonça FELICI ${ }^{4}$, Nelissa Garcia BALARIM ${ }^{5}$ \\ 1 Universidade do Oeste Paulista - UNOESTE, Curso de Engenharia Ambiental e \\ Sanitária. \\ E-mail: beatrizangelo08@yahoo.com.br, rafa.pelegrini@outlook.com, \\ thaisaquino48@hotmail.com, elson@unoeste.b, nelissa@unoeste.br.
}

RESUMO - O presente estudo da microbacia Água da Colônia no município de Presidente Venceslau- SP trata-se de uma análise dos impactos ambientais concernentes às práticas dos moradores, com a finalidade de preconizar medidas mitigatórias e recomendar modificações de hábito para conservação e estabilidade ecossistêmica. Para isso, fizeram-se necessárias algumas análises físico-químicas, visitas a campo, revisão de literatura, entre outros. Desse modo, possibilitou-se obter ciência da situação atual da microbacia, considerando as atividades dos moradores frente aos recursos naturais. Constatou-se algumas adversidades nos resultados das análises, mas de modo geral, nenhum destaque preocupante. Ademais, a observação da rotina dos moradores, fez-se possível evidenciar algumas justificativas para a perda de qualidade de vida dos mesmos, que advém de suas próprias atitudes impactantes, pois concluiu-se que quaisquer atividades nocivas ao meio ambiente, tendem a refletir-se ao ser causador.

Palavras-chave: bacia hidrográfica, impactos, medidas mitigatórias.

ABSTRACT - The present study of the Água da Colônia watershed in the municipality of Presidente Venceslaú-SP is an analysis of the environmental impacts concerning the residents' practices, with the purpose of recommending mitigation measures and recommending habit modifications for conservation and ecosystem stability. For this, some physical-chemical analysis, field visits, literature review, among others, were necessary. In this way, it was possible to obtain knowledge of the current situation of the microbasin, considering the activities of the inhabitants against the natural resources. Some adversities were found in the results of the analyzes, but in general, no worrisome highlight. In addition, the observation of the routine of the residents, it was possible to evidence some justifications for the loss of quality of life of the same ones, that comes from their own impacting attitudes, since it was concluded that any activities harmful to the environment, tend to reflect the being cause.

Keywords: hydrographic basin, impacts, mitigating measures. 


\section{INTRODUÇÃO}

É imprescindível obter ciência da importância considerável que as bacias hidrográficas representam ao meio ambiente e o quão necessário faz-se conservá-las, de modo que as interferências antrópicas não as comprometam desfavoravelmente.

Avistou-se no perímetro rural inúmeras fragilidades entorno das questões ambientais, provenientes de ações naturais porém agravadas com as ações antrópicas diárias, sendo elas provenientes do próprio trabalho campestre. Estas atividades causam de forma direta e indireta impactos ambientais muitas vezes irreparáveis e de grande escala, uma vez que uma ação local pode se tornar regional.

O objetivo deste estudo foi analisar a microbacia do córrego Água da Colônia no município de Presidente Venceslau-SP, afim de pontuar as fragilidades propondo ações de controle e melhorias. Cabe destacar que o presente estudo possui alta relevância, pois as análises, juntamente com as ações de controle, propiciam melhoria ambiental na microbacia, em que se houver tais procedimentos em todas as microbacias, a totalidade representará um progresso nas questões ambientais, acarretando em qualidade de vida aos seres humanos, que necessitam por questões biológicas e econômicas dos recursos naturais, porém, sabe-se que os mesmos são finitos e requerem preocupação.

\section{METODOLOGIA}

Para a elaboração do trabalho, conclusão de determinadas informações e sugestões de medidas de controle para os impactos ambientais observados, fez-se necessário algumas visitas em grupo no local, a fim de visualizar de forma ampla e definida os impactos ambientais existentes a partir de fotografias e por fim, coletar as amostras de água nos pontos apurados, para que posteriormente, fossem concedidas as análises físico-químicas das mesmas. Destaca-se ainda, que a natureza do trabalho foi descritiva, visto que, a partir das análises visuais e técnicas realizadas, possibilitou-se descrever o local, os impactos, as legislações concernentes e consequentemente, as mitigações de modo a potencializar os impactos positivos e mitigar os negativos.

Quanto às visitas realizadas em campo, fez-se necessário somente três visitas, pois as mesmas, foram suficientes para coletar dados, além das amostras de água.

Entretanto, devido a algumas limitações acadêmicas, não foi possível efetuar todos os parâmetros que tencionava-se, como por exemplo, os nove parâmetros necessários para apresentar o IQA (Índice de Qualidade da Água). Por isso, cabe dizer que os parâmetros analisados, tornaram-se insuficientes para a conclusão concreta de algo. Efetuou-se as análises mais básicas das quais foram permitidas, sendo: $\mathrm{pH}$ juntamente com a temperatura, condutividade, salinidade e turbidez, utilizando todos os equipamentos e reagentes pertencentes ao laboratório da instituição. Mas a priori, fez-se necessário coletar as amostras de água para os procedimentos laboratoriais.

Condizente à justificativa dos pontos escolhidos, revela-se que os pontos 1, 2 e 3 foram selecionados a fim de identificar algum indício de lançamento após uma distância das nascentes e ainda, para obter ciência da situação das nascentes quanto à parâmetros físico-químicos. Por outro lado, os pontos 4 e 5 foram escolhidos com o propósito de detectar a interferência dos afluentes ao longo do rio, ou seja, verificar de qual forma estão impactando o mesmo, seja positivamente por meio do processo de autodepuração por exemplo, ou negativamente, potencializando ou causando determinado impacto.

Após seguir todas as premissas para uma coleta eficiente, as amostras foram levadas à instituição para então serem analisadas em laboratório. Sobressai-se que as análises realizadas obedeceram a um padrão para maior precisão e confiabilidade nos resultados obtidos; desse modo, todos os equipamentos foram anteriormente calibrados e todos os béqueres utilizados para inserção das amostras, foram previamente lavados com as mesmas. Além disso, os discentes do grupo responsáveis pelas análises fizeram uso do jaleco e seguiram todas as outras exigências laboratoriais.

A partir disso, obteve-se os valores desejados para supor algum possível impacto, ou seja, obter alguma evidência indicativa e não decisiva, pois como já dito, a quantidade de parâmetros foram insuficientes para concluir algo. Ademais, destaca-se que a bibliografia composta pelos métodos descritos acima foi Standard Methods for the Examination of Water and Wastewater. 


\section{RESULTADOS E DISCUSSÕES}

Os valores médios obtidos de $\mathrm{pH}$, condutividade, salinidade e turbidez da água estão expressos na tabela a seguir (Tabela 1).

Tabela 1. Parâmetros Físicos e Químicos de Qualidade da Água

\begin{tabular}{c|c|c|c|c}
\hline Pontos de Coleta & $\mathbf{p H}$ & Condutividade & Salinidade & Turbidez \\
\hline P1 & 6,41 & 17,1 us & - & $5,52 \mathrm{NTU}$ \\
P2 & 7,76 & 100,4 us & 0,04 & $2,26 \mathrm{NTU}$ \\
\hline P3 & 6,09 & 18,2 us & - & $4,49 \mathrm{NTU}$ \\
\hline P4 & 5,48 & 19,9 us & - & $7,11 \mathrm{NTU}$ \\
\hline P5 & 6,54 & 26,5 us & - & $14,9 \mathrm{NTU}$ \\
\hline P6 & 6,97 & 160,2 us & 0,07 & $0,04 \mathrm{NTU}$ \\
\hline
\end{tabular}

Fonte: (Autores, 2018).

Observa-se que os valores de $\mathrm{pH}$ nos trechos P2 e P4 apresentam uma mudança significativa nos valores. Em decorrência desses valores, pode-se deduzir (Supor) que algum fator externo possa vir estar influenciando nos pontos, assim ocasionando o aumento e a queda, respectivamente.

Considera-se o pH como um parâmetro importante à qualidade da água e à vida aquática e devido a isso, mudanças abruptas de valores devem ser observadas com atenção. Ressalta-se que alguns importantes fatores que podem influenciar nos valores de pH são: Falta de área de preservação permanente (App), chuvas ácidas, efluentes dispostos de maneira irregular (Sem o devido tratamento anterior ao lançamento), águas de escoamento, etc. Segundo a resolução CONAMA no 357/2005, em águas superficiais, o $\mathrm{pH}$ deve estar em uma faixa de 6 a 9; dessa forma, o ponto $\mathrm{P} 2$ encontra-se em conformidade com a legislação pertinente e o P4 inferior aos níveis exigidos.

Tratando-se da condutividade e salinidade, ambos os parâmetros estão diretamente interligados, quanto maior a condutividade, consequentemente maior o nível de salinidade; fato que constata-se nos pontos P2 e P6 que apresentam o maior nível de condutividade e salinidade, pois os sais presentes nas águas superficiais condizem à razão principal pelo aumento da condutividade da mesma (Considerando-se um aumento abrupto em comparação aos outros valores de condutividade obtidos). Para efeito, a resolução CONAMA na $357 / 2005$ declara valores inferiores a 0,5 \% para águas doces, destarte as amostras obedecem ao valor exigido, sobretudo tratando-se da amostra do ponto 6 , do qual, refere-se a água utilizada para consumo.

Referente aos níveis de turbidez, os mesmos também encontram-se seguindo os regimentos da legislação, visto que, os valores para turbidez é até 100 NTU para águas superficiais classe 2 e o maior valor apresentado pelas análises laboratoriais foi no ponto $\mathrm{P} 5$, em que mesmo assim, enquadrou-se na legislação vigente.

Os parâmetros analisados nos pontos $\mathrm{P} 1$, P2, P3, P5, e P6 estão obedecendo a legislação constituinte, exceto o ponto $\mathrm{P} 4$ devido o $\mathrm{pH}$ do mesmo estar abaixo do exigido, mas mesmo com essa adversidade, o corpo hídrico analisado com os parâmetros apresentados não retrata um indício de poluição, não tornando-se uma decisão conclusiva, pois não foram abordados todos os critérios para o Índice de Qualidade da Água (IQA)

\subsection{MEDIDAS MITIGATÓRIAS}

A tabela a seguir (Tabela 2) apresenta os aspectos, seguido pelos impactos e suas respectivas medidas mitigatórias e programas ambientais. 
Tabela 2. Medidas Mitigadoras

\begin{tabular}{|c|c|c|}
\hline Aspectos & Impactos & $\begin{array}{c}\text { Medidas mitigadoras e programas } \\
\text { ambientais }\end{array}$ \\
\hline \multirow{4}{*}{ Interferências no solo } & Compactação do Solo & $\begin{array}{l}\text { Implantação de cercas em torno do } \\
\text { Córrego e em áreas mais vulneráveis, } \\
\text { como as nascentes. }\end{array}$ \\
\hline & \multirow[t]{2}{*}{ Processos Erosivos } & $\begin{array}{l}\text { Execução de obras complementares de } \\
\text { drenagem em torno de áreas mais } \\
\text { vulneráveis, bem como o plantio de } \\
\text { forração vegetal; }\end{array}$ \\
\hline & & $\begin{array}{l}\text { Desenvolvimento do processo de } \\
\text { recomposicão florestal das áreas }\end{array}$ \\
\hline & Assoreamento & $\begin{array}{l}\text { verdes/Áreas de Preservação Permanente } \\
\text { visando o controle de processos erosivos. }\end{array}$ \\
\hline \multirow{3}{*}{$\begin{array}{l}\text { Fragmentos de } \\
\text { Vegetação }\end{array}$} & Diminuição de Habitats & Recuperação de áreas degradadas; \\
\hline & Perda da Cobertura Vegetal & $\begin{array}{l}\text { Recomposição de mata ciliar/APP em } \\
\text { torno do curso d'água, sistemas espécies } \\
\text { arbóreas nativas, de modo a seguir o } \\
\text { exposto no Código Florestal; }\end{array}$ \\
\hline & $\begin{array}{l}\text { Redução da vazão do Córrego } \\
\text { Água da Colônia; }\end{array}$ & Programa de Monitoramento Ambiental. \\
\hline \multirow{4}{*}{$\begin{array}{c}\text { Geração, } \\
\text { Armazenamento e } \\
\text { Descarte Irregular de } \\
\text { Resíduos Sólidos }\end{array}$} & $\begin{array}{l}\text { Incineração de Resíduos Sólidos } \\
\text { (Poluição do Ar) }\end{array}$ & $\begin{array}{l}\text { Implementação de Programas de } \\
\text { Educação e Saúde Ambiental; }\end{array}$ \\
\hline & \multirow[t]{2}{*}{ Poluição do Solo } & $\begin{array}{l}\text { Incentivo a adoção de políticas públicas e } \\
\text { saneamento básico; }\end{array}$ \\
\hline & & $\begin{array}{l}\text { Programa de Monitoramento e } \\
\text { Manutenção de Córregos; }\end{array}$ \\
\hline & $\begin{array}{l}\text { Poluição do Córrego Água da } \\
\text { Colônia e Lençol Freático }\end{array}$ & $\begin{array}{l}\text { Gerenciamento de resíduos sólidos } \\
\text { (Coleta Tratamento e Disposição). }\end{array}$ \\
\hline \multirow{4}{*}{$\begin{array}{l}\text { Interferência em Cursos } \\
\text { D'água Naturais }\end{array}$} & $\begin{array}{l}\text { Alteração da qualidade da água } \\
\text { superficial; }\end{array}$ & $\begin{array}{l}\text { Prevenção e controle dos processos } \\
\text { erosivos; }\end{array}$ \\
\hline & \multirow{3}{*}{ Diminuição da Vazão do Córrego } & Recuperação de áreas degradadas; \\
\hline & & Preservação das nascentes; \\
\hline & & Recomposição de mata ciliar. \\
\hline \multirow[t]{4}{*}{ Meio Social } & \multirow{4}{*}{ Ausência de Políticas Públicas } & $\begin{array}{c}\text { Promover políticas públicas, tendo } \\
\text { sempre em vista uma fiscalização efetiva; }\end{array}$ \\
\hline & & Plano diretor; \\
\hline & & Promover educação ambiental; \\
\hline & & $\begin{array}{l}\text { Política de saneamento e saúde } \\
\text { ambiental. }\end{array}$ \\
\hline
\end{tabular}

Fonte: (Autores, 2018). 


\section{CONCLUSÃO}

Tendo em vista os aspectos observados, entende-se $o$ quão fundamental faz-se a conservação dos recursos naturais, visto que, quaisquer interferências antropológicas refletem na qualidade de toda a bacia hidrográfica da qual está situado. Assim sendo, notou-se algumas negligências na microbacia em estudo, das quais, com o passar do tempo e com a prática contínua das mesmas, podem fomentar em diversos impactos ambientais, alguns sendo até irreversíveis. Ressalta-se ainda que há algumas práticas realizadas que suscitam em problemas no âmbito da salubridade dos próprios moradores, como por exemplo, a incineração de resíduos sólidos e o consequente surgimentos de animais indesejáveis, que podem provocar problemas respiratórios, acidentes e contaminação de água e solo, dos quais, podem propiciar inúmeras adversidades aos residentes. Logo, a partir de todas as análises realizadas, percebe-se que qualquer atividade que venha a causar alguma nocividade ao meio ambiente, tende-se a refletir aos humanos, seja na limitação dos recursos naturais, bem como na saúde dos mesmos. Desse modo, faz-se imprescindível a gestão ambiental adequada, a fim de tornar a bacia mais próxima da sustentabilidade, de modo que seja possível usufruí-la sem causar algum dano permanente.

\section{REFERÊNCIAS}

ATLAS, Desenvolvimento Humano no Brasil. Presidente Venceslau, SP. Disponível em: <http://atlasbrasil.org.br/2013/pt/perfil_m/presi dente-venceslau_sp\#habitacao $>$. Acesso em: Abr. de 2018.I

BORGES, Waleska. O Globo. Lixo acumulado a céu aberto pode causar doenças à população do Rio. Disponível em: <https://oglobo.globo.com/rio/lixo-acumuladoceu-aberto-pode-causar-doencas-populacao-dorio-11798416>. Acesso em: Mai. de 2018.

CARDOSOCARDOSO, Fernando Henrique; CARVALHO, José Carlos. Decreto no 4.497, de 10 de julho de 2012. Disponível em: $<$ http://www.planalto.gov.br/ccivil 03/decreto/2002/d4297.htm>. Acesso em: Mai. de 2018.
CARDOSO, Fernando Henrique; KRAUSE, Gustavo. Lei no 9433, de 8 de janeiro de 1997. Disponível em:

<http://www.mma.gov.br/port/conama/legiabre. cfm?codlegi=370>. Acesso em: Mai. de 2018.

DAL BEM, Júlio César et al. Revista Brasileira de Energia Solar. Solução para bombeamento de água em propriedades rurais utilizando energia solar fotovoltaica. Disponível em: $<$ https://rbens.emnuvens.com.br/rbens/article/d ownload/146/144>. Acesso em: Mai. de 2018.

EDUCAÇÃOEDUCAÇÃO, Portal. Biologia. Salinidade da água do mar. Disponível em: <https://www.portaleducacao.com.br/conteudo/ artigos/biologia/salinidade-na-agua-domar/33758>. Acesso em: Mai. de 2018.

GEOGEO, Data. Sistema Ambiental Paulista. Disponível em: $<$ http://datageo.ambiente.sp.gov.br/app/>. Acesso em: Abr. de 2018

IBGE, Instituto Brasileiro de Geografia e Estatística. Presidente Venceslau. Disponível em: $<$ https://cidades.ibge.gov.br/brasil/sp/presidente -venceslau/panorama>. Acesso em: Abr. de 2018.

LABORLABOR. Equipamentos para laboratórios. Condutivímetro. Como medir condutividade. Disponível em: $<$ http://www.splabor.com.br/blog/condutivimetr o-2/condutivimetro-como-medir-acondutividade/>. Acesso em: Mai. de 2018.

LORENZOLORENZO, Mariana. Ideias Fora da Caixa. Pedologia-Perfil e Camadas/Horizontes Dos Solos. Disponível em: $<$ https://marianaplorenzo.com/2010/10/15/pedo logia-perfil-e-camadashorizontes-dos-solos/>. Acesso em: Mai. de 2018.

MAPMAP, Topographic. Presidente Prudente. Disponível em: <http://pt-br.topographicmap.com/places/Presidente-Prudente1342371/>. Acesso em: Abr. de 2018.

MENDES, Mariane. Brasil Escola. Aula prática sobre condutividade elétrica das substâncias. Disponível em: $<$ https://educador.brasilescola.uol.com.br/estrat egias-ensino/aula-pratica-sobre-condutividade- 
eletrica-das-substancias.htm>. Acesso em: Mai. de 2018.

MUNHOZ, Barros; MACHADO, Campos; GALVÃO, Estevão. Lei no 15.684, de 14 de janeiro de 2015. Disponível em: <https://www.al.sp.gov.br/repositorio/legislacao /lei/2015/lei-15684-14.01.2015.html>. Acesso em: Mai. de 2018.

PEÇONHENTOSPEÇONHENTOS, Animais. Animais Peçonhentos. Disponível em: <http://animaispeconhentos.info/>. Acesso em: Mai. de 2018

PORTAL, Tratamento de Água. Determinação da Turbidez. Determinação da turbidez pelo método nefelométrico. Disponível em: <https://www.tratamentodeagua.com.br/artigo/ determinacao-da-turbidez/>. Acesso em: Mai. de 2018.

PREFEITURAPREFEITURA MUNICIPAL. Plano de Gestão Integrada de Resíduos Sólidos de Presidente Venceslau - SP. Disponível em: <http://arquivos.ambiente.sp.gov.br/cpla/2017/0 5/presidente-venceslau.pdf $>$. Acesso em: Abr. de 2018.

ROUSSEFFROUSSEFF, Dilma. Lei no 12.651 de 25 de maio de 2012. Disponível em: <http://www.planalto.gov.br/ccivil_03/_ato20112014/2012/lei/l12651.htm>. Acesso em: Mai. de 2018.
SILVASILVA, André Luis da Silva. Info Escola. Turbidez da Água. Disponível em: https://www.infoescola.com/quimica/turbidezda-agua/>. Acesso em: Mai. de 2018.

SILVA, Marina. Resolução CONAMA no 357, de 17 de Março de 2005. Disponível em: <http://www.mma.gov.br/port/conama/legiabre. cfm?codlegi=459>. Acesso em: Mai. de 2018.

SOUZASOUZA, Fábio. Vivoverde. Queimadas prejudicam o meio ambiente e a saúde humana. Disponível em: <http://vivoverde.com.br/queimadasprejudicam-o-meio-ambiente-e-a-saudehumana/>. Acesso em: Mai. de 2018

SOUZA, Joice Silva. InfoEscola. Eutrofização. Disponível em: $<$ https://www.infoescola.com/ecologia/eutrofiza cao/>. Acesso em: Mai. de 2018.

SOUZA, Líria Alves de. Mundo Educação. Você sabe o que significa pH? Disponível em: $<$ https://mundoeducacao.bol.uol.com.br/quimica /voce-sabe-que-significa-ph-.htm>. Acesso em: Mai. de 2018.

TODA, Matéria. $\mathbf{O}$ que é $\mathbf{p H}$ ? Disponível em: $<$ https://www.todamateria.com.br/o-que-e-ph/>. Acesso em: Mai. de 2018. 